JRC2006-94038

\title{
THE EFFECT OF WEDGE FRICTION CONDITIONS ON THE DYNAMIC WHEEL-RAIL CONTACT FORCE ON SHORT WAVELENGTH DEFECTS
}

\author{
Yan Quan Sun \\ Colin Cole \\ Centre for Railway Engineering \\ Central Queensland University \\ North Rockhampton, QLD 4702 \\ Australia \\ Tel: 617 49309287, Email mailto:y.q.sun@.cqu.edu.au
}

\begin{abstract}
For wagons with three-piece bogies, the suspension dynamic characteristics are largely dependent on the friction condition of the wedge dampers. The influence of changes in wedge friction conditions on the dynamic wheel load is investigated. Comprehensive wagon-track modelling has been developed for the analysis. Simulations show that a small friction coefficient on the wedge contact surfaces can lead to the severe resonance of suspension system, causing large dynamic wheel loads and high levels of wheel unloading while with a large friction coefficient, suspension resonance is restricted, leading to smaller dynamic wheel loads.
\end{abstract}

\section{INTRODUCTION}

It has been well known that wagon and track dynamics originates from the dynamic interactions between wagon and track at the wheel-rail interface.

The dynamic wheel load is an important parameter in the assessment of wagon and track operation conditions. For example, Jenkins et al. [1] presented $\mathrm{P}_{1}$ and $\mathrm{P}_{2}$ forces from dynamic wheel load due to rail dipped joints, and limits were suggested for these forces. Many theoretical and experimental investigations [1] [18] have been done to determine the dynamic wheel load. The results show that the dynamic wheel load is dependent on track geometry irregularities (cross level, alignment, top surface and gauge variations), wheel and rail defects (wheel flats, wheel burns, rail dipped joints, and rail corrugations), vehicle speed, static wheel load and unsprung mass, and track modulus and track mass.

In our ongoing research on the vertical suspension dynamic characteristics of the three-piece bogie due to track geometry irregularity - top surface variation with short wavelength, it has been found that the suspension dynamics is largely dependent on friction condition of the wedge dampers. For this aspect of research, a detailed simulation analysis has been carried out using a model of wagon-track dynamics interaction. In this model, the wagon is modelled using 66 degrees of freedom, accounting for the three dimensional movements of all wagon components. The track is modelled with the rails described using Timoshenko beams and discretely supported by the spring and damper elements representing the elasticity of pads, fasteners and ballast. Assumed track geometry irregularity - top surface profile with 15 parallel perturbations with a wavelength of $1.676 \mathrm{~m}$ in length, and a vertical amplitude to the track surface of $12 \mathrm{~mm}$ peak to peak, is used. Wagon speed is in the range of $12.7-60 \mathrm{kph}$ so that the track input frequency is in the range of $2-10 \mathrm{~Hz}$. Suspension dynamic characteristics and the dynamic wheel loads corresponding to the wedge friction conditions at the different track input frequencies are discussed.

\section{WAGON-TRACK MODELLING}

In this section, the modelling of vehicle-track system dynamics for the investigation on suspension dynamic characteristics of three-piece bogie is given. The dynamic vehicle-track system is divided into three subsystems - vehicle, track and wheel-rail contact, which are described in the following subsections respectively.

\subsection{Wagon Subsystem}

Wagon subsystem includes one wagon car body, two bolsters, four sideframes and four wheelsets. The wagon car body rests on two bolsters through two centre bowls and four constant-contact side bearings. Each centre bowl is modeled as four point contacts through the spring and friction elements along the longitudinal, lateral and vertical directions. The constant-contact side bearing is simplified as a spring element in the vertical direction. In the longitudinal direction, the car body is connected with two couplers, which are represented as 
springs. The bolster is supported by the suspensions. The sideframe is an intermediate structure that provides seating for the suspensions and connects to the wheelsets through steelsteel contact that is represented as stiff springs. Nonlinear connection characteristics such as lift-off among wagon components are fully considered. In this paper, the "constantdamping" wedge located in the sideframe is considered, and its modelling takes account of the wedge inertia and is described as follows:

Fig. 1 shows the friction wedge modelling.

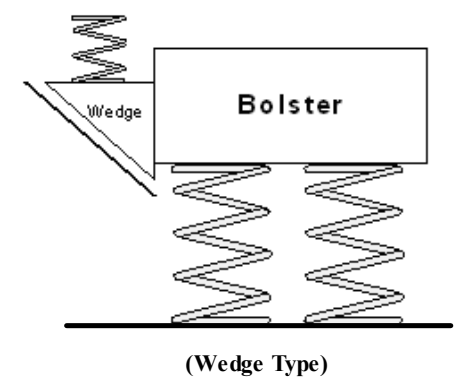

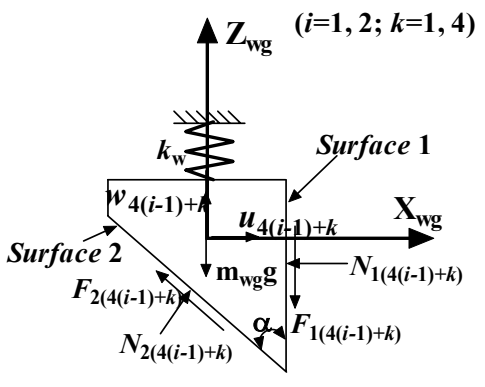

(Wedge Modelling)
(Wedge Numbering)

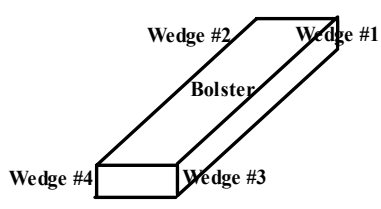

Fig. 1 Friction Wedge Modelling

In Fig. 1, $N_{1(4(i-1)+k)}$ and $F_{1(4(i-1)+k)}$, and $N_{2(4(i-1)+k)}$ and $F_{2(4(i-1)+k)}$ are the normal and friction forces on the contact surface 1 and contact surface 2, the subscripts $i$ and $k$ represent the numbers of bolsters and wedges respectively, $u_{4(i-1)+k}$ and $w_{4(i-1)+k}$ are the longitudinal and vertical relative displacements of wedge to sideframe, and $\alpha$ is the wedge angle. follows:

The assumptions concerning wedge friction are made as

- Surface 1 and 2 are always in contact, and

- Surface 1 and 2 are in sliding situation (e.g. friction is 'saturated' on both surfaces).

The second assumption is consistent with that used in many publications [19]-[23]. According to above assumptions, $u_{4(i-1)+k}$ and $w_{4(i-1)+k}$ satisfy the following sliding constraints:

$$
\left\{\begin{array}{r}
u_{4(i-1)+k}=-w_{4(i-1)+k}(-1)^{k} \cdot \tan \alpha \quad(i=1,2 ; k=1,4) \\
\text { from contact surface } 2 \\
u_{4(i-1)+k}=\left[x_{6 i+1}+x_{6 i+5} \cdot\left(H_{b w}-\Delta w_{i k}\right)+x_{6 i+6} \cdot B_{s s}(-1)^{j}\right]- \\
\left(x_{12 i+6 j+1}+x_{12 i+6 j+5} \cdot H_{s f w}\right) \\
(j=1,2 ; \text { if } k=1 \text { or } 2, j=1 ; \text { if } k=3 \text { or } 4, j=2) \\
\text { from contact surface } 1
\end{array}\right.
$$

In which $x_{6 i+1}, x_{6 i+5}$ and $x_{6 i+6}$ are the longitudinal displacement, the pitch and yaw rotations of bolster; $x_{12 i+6 j+1}$ and $x_{12 i+6 j+5}$ are the longitudinal displacement and the pitch rotation of sideframes; The subscripts $j$ represents the numbers of sideframes; $B_{s s}$ is the lateral semi distance between two wedges; $H_{b w}$ is the vertical distance between mass centres of wedge and bolster at the static situation; $\Delta w_{i k}$ is the vertical relative displacement between wedge and bolster; and $H_{s f w}$ are the vertical distance between mass centres of wedge and sideframe. So, the dynamic equations of friction wedge along longitudinal and vertical directions are:

$$
\left\{\begin{array}{c}
m_{w g}\left[\ddot{u}_{4(i-1)+k}+\left(\ddot{x}_{12 i+6 j+1}+\ddot{x}_{12 i+6 j+5} \cdot H_{s f w}\right)\right]=-N_{1(4(i-1)+k)}(-1)^{k}+ \\
N_{2(4(i-1)+k)}(-1)^{i} \cdot \cos \alpha-F_{2(4(i-1)+k)}(-1)^{i} \cdot \sin \alpha \\
m_{w g}\left[\ddot{w}_{4(i-1)+k}+\left(\ddot{x}_{12 i+6 j+3}+\ddot{x}_{12 i+6 j+5} L_{w w}(-1)^{i}\right)\right]=-F_{1(4(i-1)+k)}+ \\
N_{2(4(i-1)+k)} \sin \alpha+F_{2(4(i-1)+k)} \cdot \cos \alpha-k_{w}\left(w_{0}+w_{(4(i-1)+k)}\right)-m_{w g} g
\end{array}\right.
$$

In which $m_{w g}$ is the mass of friction wedge, and $L_{w w}$ are the semi longitudinal distance between two wedges.

In Eq. (2), the wedge friction force on contact surface 1 is calculated using the following Eq. (3).

$$
F_{1(4(i-1)+k)}= \begin{cases}-N_{1(4(i-1)+k)} \cdot \mu & \text { if } V_{r} \leq-\varepsilon \\ \frac{\mu / \varepsilon \cdot V_{r} \cdot N_{1(4(i-1)+k)}}{\sqrt{\left(1+\left(V_{r} / \varepsilon\right)^{4}\right) / 2}} & \text { if }-\varepsilon<V_{r}<\varepsilon \\ N_{1(4(i-1)+k)} \cdot \mu & \text { if } V_{r} \geq \varepsilon\end{cases}
$$

In which $V_{r}$ is relative velocity between bolster and sideframe, $\mu$ is the friction coefficient of wedge, and $\varepsilon$ is the relative velocity magnitude $(5 \sim 7 \mathrm{~mm} / \mathrm{s})$ above which the coefficient of friction becomes definitively constant. 
Except for the suspension elements including wedge dampers, all the other components of wagon are considered as rigid bodies with masses and mass inertia moments along the three Cartesian coordinate directions. All movements of the wagon subsystem are taken into account. The total degrees of freedom (Dofs) required to describe the longitudinal, lateral and the vertical displacements and rotations of the full wagon are listed in Table 1 in which $u, v, w$ are the linear displacements and $\phi_{x}, \phi_{y}, \phi_{z}$ are the rotations about $X, Y$ and $Z$ axes respectively. As shown, there are 66 Dofs required to fully define the wagon dynamics.

Table 1 Degrees of Freedom of Wagon

\begin{tabular}{|l|c|c|c|c|c|c|}
\hline Components & $u$ & $v$ & $w$ & $\phi_{x}$ & $\phi_{y}$ & $\phi_{z}$ \\
\hline $\begin{array}{l}\text { Wagon Car } \\
\text { Body }\end{array}$ & $\times$ & $\times$ & $\times$ & $\times$ & $\times$ & $\times$ \\
\hline Bolster & $\times$ & $\times$ & $\times$ & $\times$ & $\times$ & $\times$ \\
\hline Sideframe & $\times$ & $\times$ & $\times$ & $\times$ & $\times$ & $\times$ \\
\hline Wheelset & $\times$ & $\times$ & $\times$ & $\times$ & $\times$ & $\times$ \\
\hline Total Dofs & \multicolumn{7}{|c|}{$1 \times 6+2 \times 6+4 \times 6+4 \times 6=66$} \\
\hline
\end{tabular}

The equations of dynamic equilibrium can be written using multi-body mechanics method as shown below:

$$
\mathbf{M}_{\mathbf{w}} \ddot{d}_{W}+\mathbf{C}_{\mathbf{w}} \dot{d}_{W}+\mathbf{K}_{\mathbf{w}} d_{W}=F_{W T}
$$

Where $\mathbf{M}_{\mathbf{w}}, \mathbf{C}_{\mathbf{w}}$ and $\mathbf{K}_{\mathbf{w}}$ are the mass, damping and stiffness matrices of the wagon subsystem. These matrices are $66 \times 66$ respectively. $\boldsymbol{d}_{\boldsymbol{W}}$ is the displacement vector of the wagon subsystem, and $\boldsymbol{F}_{\boldsymbol{W} T}$ is the wheel-rail interface force vector consisting of the wheel-rail normal contact forces, tangent creep forces and creep moments about normal direction in the wheel-rail contact plane.

\subsection{Track Subsystem}

The track subsystem is considered as the discretely supported distributed-parameter track modelling with one layer. In the model, all the track components beneath rails used in the conventional ballasted heavy haul track structure are simplified as the spring and damper elements, which discretely support the rails at an interval of sleeper spacing.

The lateral and the vertical bending and shear deformations of the rail beam are described using Timoshenko beam theory extended by considering the torque of the rail beam. Thus, there are five Dofs at any point along the longitudinal neutral axis of the rail beam, namely, lateral and vertical displacements and rotations about the lateral $(Y)$ and vertical $(Z)$ axes and the torsional rotation about the longitudinal $(X)$ axis used in the formulation of the rail beam. For simplicity, the dynamic equilibrium equations of the rail beam has been expanded using Fourier series in the longitudinal $(X)$ direction by assigning equal number of terms $\left(n_{m}\right.$, also known as the number of modes of the rail beam) for both the linear displacements and the angular rotations. The governing equations of dynamic equilibrium for the track are expressed in the following matrix form:

$$
\mathbf{M}_{\mathrm{T}} \ddot{d}_{T}+\mathbf{C}_{\mathrm{T}} \dot{d}_{T}+\mathbf{K}_{\mathrm{T}} d_{T}=\widetilde{F}_{W T}
$$

In which $\mathbf{M}_{\mathbf{T}}, \mathbf{C}_{\mathbf{T}}$ and $\mathbf{K}_{\mathbf{T}}$ (each of size $10 n_{m} \times 10 n_{m}$ ) are the mass, damping and stiffness matrices of the track subsystem. The vector $\boldsymbol{d}_{T}$ contains displacement of the track subsystem that includes the modal and physical displacements, and $\widetilde{\boldsymbol{F}}_{\boldsymbol{W} \boldsymbol{T}}$ is the combined wheel-rail interface force vector.

\subsection{Wheel-Rail Interface Subsystem}

Under rolling contact the wheel and the rail produce contact forces in the normal direction on the wheel-rail contact plane. In addition, creep forces are generated in the longitudinal and the lateral directions tangential to the contacting plane, and creep moment about the normal direction. In this paper, the normal contact force $F_{n w r}$ due to the wheel-rail rolling contact is determined using Hertz contact theory and can be expressed in Eq. (6):

$$
F_{n w r}=\left\{\begin{array}{cl}
C_{H}\left[w_{R}-w_{w}-\mu(x)\right]^{3 / 2} & \text { if } w_{R}-w_{w}-\mu(x)>0 \\
0 & \text { if } w_{R}-w_{w}-\mu(x)<0
\end{array}\right.
$$

In which $C_{H}$ is Hertz contact coefficient, $w_{R}$ is the vertical displacement of rail at the contact point, $w_{w}$ is the vertical displacement of wheel at the contact point, and $\mu(x)$ is the function representing the track geometry irregularity.

\section{SIMULATION SYSTEM PARAMETERS}

\subsection{Wagon-Track Parameters}

A wagon and track system was selected for examining the dynamic behaviours of suspension systems with two types of friction wedges. In the model, the length of track is chosen to be 146 sleeper spacings because it would be considered that the deflections and their differential values are closed to zero at two boundary sections when the wagon travels a distance of 55 meters. The list of some important parameters of the system is provided in Table 2 . The model containing the system of one wagon and a section of track results in 1266 equations of motion as described:

Number of Dof used for one wagon $=66$;

Number of modes for the rail beams $=120$;

Total Dof $=66+120 \times 10=1266$. 
Table 2 Some Parameters for a Wagon and Track System

\begin{tabular}{|l|l|}
\hline Parameter & Value \\
\hline Wagon & \\
\hline Wagon car body mass & $48050 \mathrm{~kg}$ \\
\hline Mass of bolster & $365 \mathrm{~kg}$ \\
\hline Mass of sideframe & $447.5 \mathrm{~kg}$ \\
\hline Wheelset mass & $1120 \mathrm{~kg}$ \\
\hline Stiffness coefficient of suspension along Z axis & $2.555 \times 10^{6} \mathrm{~N} / \mathrm{m}$ \\
\hline Semi distance of two bogie mass centres & $5.18 \mathrm{~m}$ \\
\hline $\begin{array}{l}\text { Semi lateral distance between the left and the right } \\
\text { suspensions }\end{array}$ & $0.8001 \mathrm{~m}$ \\
\hline Semi wheelset base & $0.8375 \mathrm{~m}$ \\
\hline Mass of friction wedge & $8 \mathrm{~kg}$ \\
\hline Stiffness coefficient of wedge spring & $146 \times 10^{3} \mathrm{~N} / \mathrm{m}$ \\
\hline Wedge angle & $0.654 \mathrm{rad}$ \\
\hline Reference preload of wedge spring & $30 \mathrm{kN}$ \\
\hline Track & \\
\hline Rail mass per meter & $60 \mathrm{~kg} / \mathrm{m}$ \\
\hline Sleeper spacing & $0.685 \mathrm{~m}$ \\
\hline Track modulus & $40 \mathrm{MPa}$ \\
\hline Wheel-Rail Interface & \\
\hline Hertz spring constant & $0.87 \times 10^{\mathrm{II}} \mathrm{N} / \mathrm{m}^{3 / 2}$ \\
\hline
\end{tabular}

\subsection{Track Geometry Irregularity}

In order to obtain the wagon bounce mode only, the top surface irregularity shown in Fig. 2 is used. Using sinusoidal track irregularity profiles different wagon speeds can be selected to excite the dynamic responses of bogie suspensions at different frequencies for the wagon bounce mode only, i.e., $v$ $=f \lambda(v=$ velocity $(\mathrm{m} / \mathrm{s}), f=$ frequency $(\mathrm{Hz}), \lambda=$ wavelength $(m)$ ). The depth of the irregularity is given by the dimension $a$. In this paper, a wavelength of $1.676 \mathrm{~m}$ equal to the wheelset base, a depth $a$ of $12 \mathrm{~mm}$, and 15 parallel perturbations are selected. Bogie pitch motions are excluded as vertical axle motions are synchronised. Wagon speed is in the range of 12.7 $-60 \mathrm{kph}$ so that the track input frequency is in the range of $2-$ $10 \mathrm{~Hz}$.

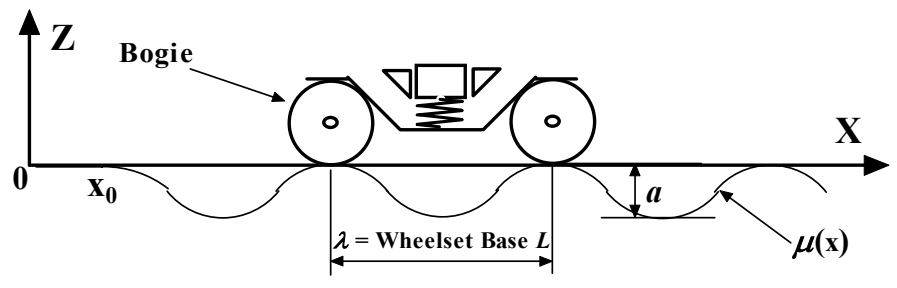

Bogie Bounce

Fig. 2 Top Surface Irregularity

The sinusoidal track irregularity profile $\mu(x)$ in Eq. (6) can be expressed as:

$$
\mu(x)=\frac{a}{2}\left\{1-\cos \left[2 \pi\left(x-x_{0}\right) / \lambda\right]\right\}
$$

\section{CHARACTERISTICS OF DYNAMIC RESPONSES}

The simulations have been completed for the bogie bounce modes over a range of track input frequencies from 2 to $10 \mathrm{~Hz}$. In the simulations, the friction condition on wedge surfaces was varied. The friction coefficients with $0.1,0.2$ and 0.3 were chosen respectively.

Figs. 3 (a) and (b), 4 (a) and (b), and 5 (a), (b) and (c) show the dynamic responses - vertical suspension forces, dynamic wheel load factor (dynamic wheel load divided by the static wheel load) and vertical wedge friction forces around the location of friction wedge \#1 with the wedge friction coefficients of $0.1,0.2$ and 0.3 at the track input frequencies of $2.3 \mathrm{~Hz}, 3 \mathrm{~Hz}$ and $6 \mathrm{~Hz}$ respectively.

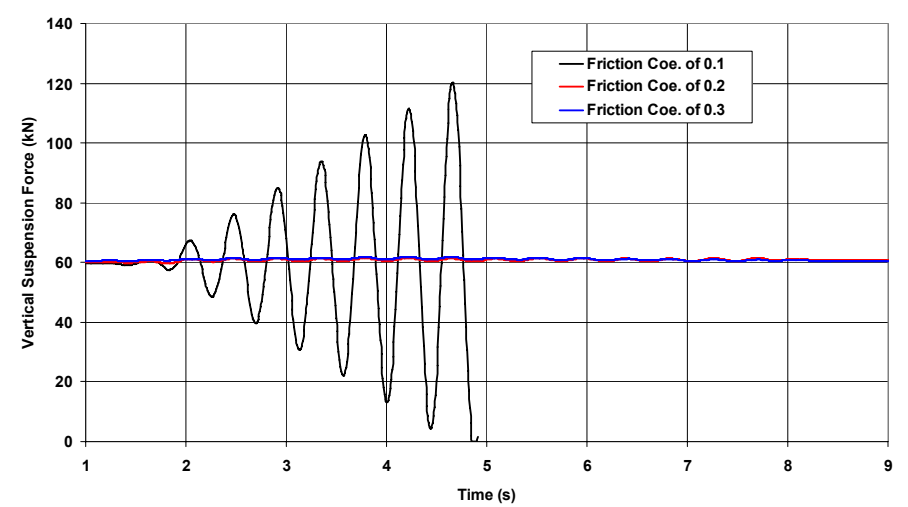

(a) Suspension Force

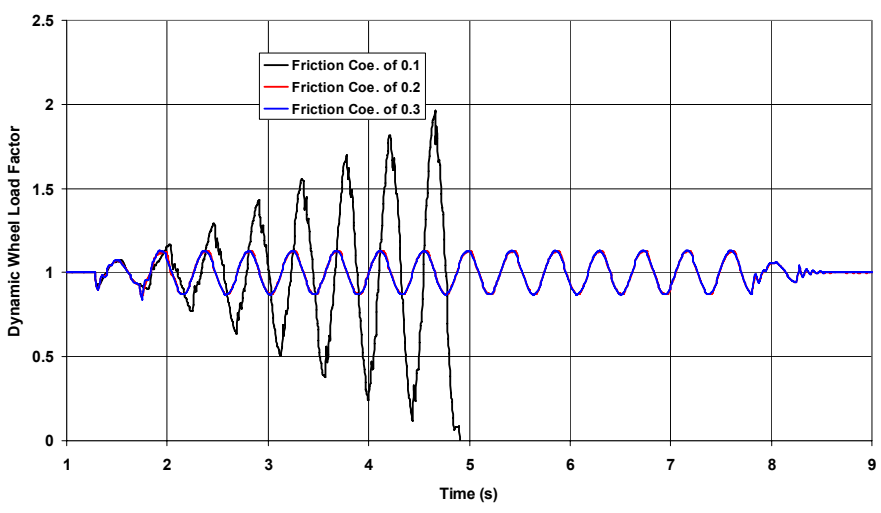

(b) Wheel Dynamic Load

Fig. 3 Dynamic Responses at $2.3 \mathrm{~Hz}$

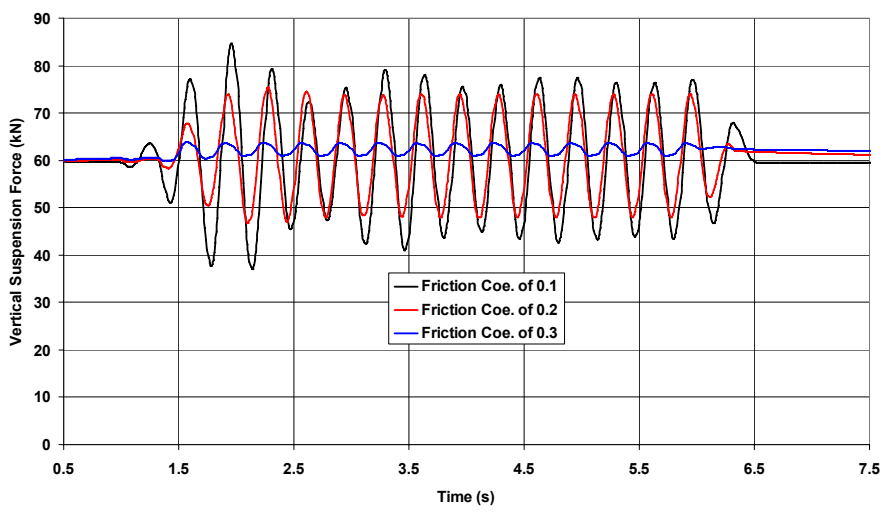

(a) Suspension Force 


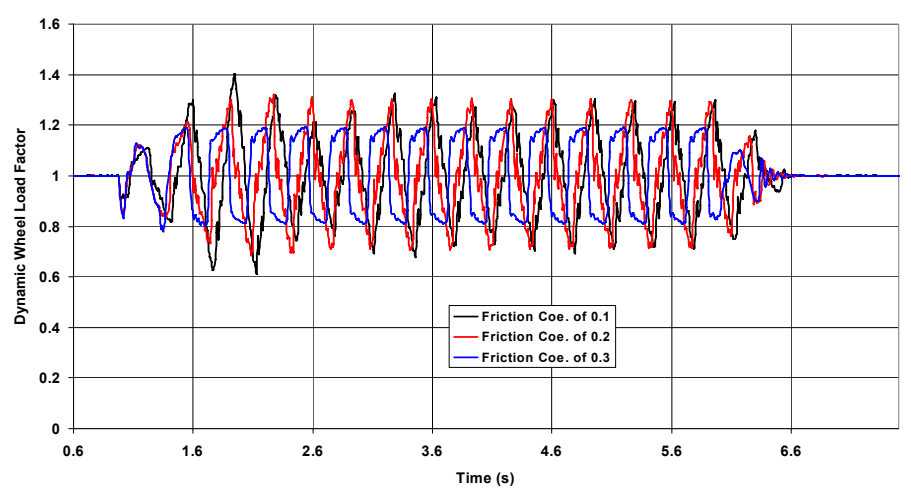

(b) Wheel Dynamic Load

Fig. 4 Dynamic Responses at $3 \mathrm{~Hz}$

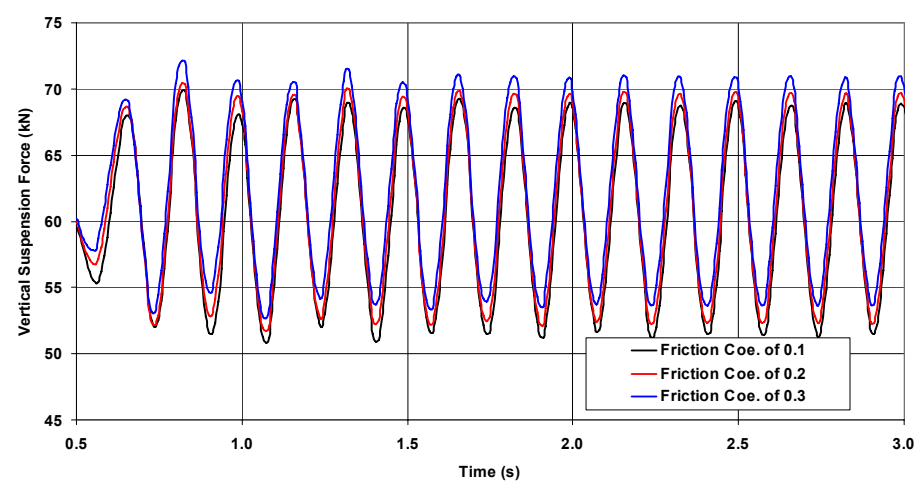

(a) Suspension Force

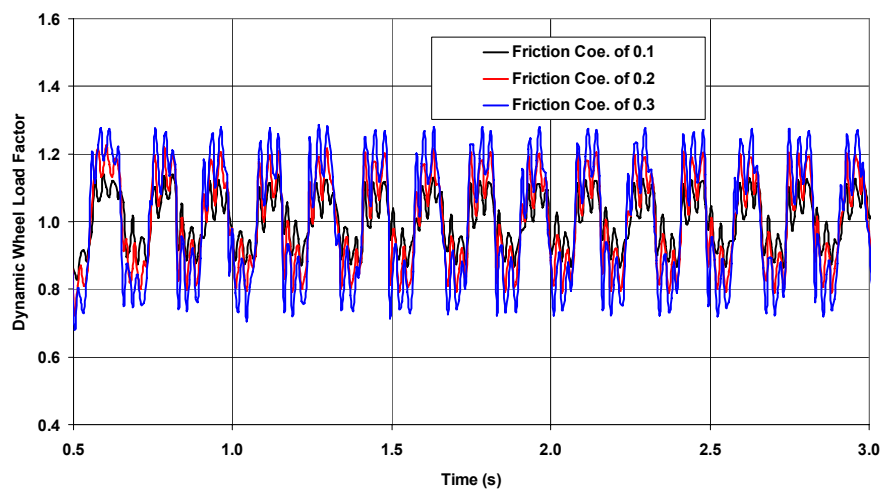

(b) Wheel Dynamic Load

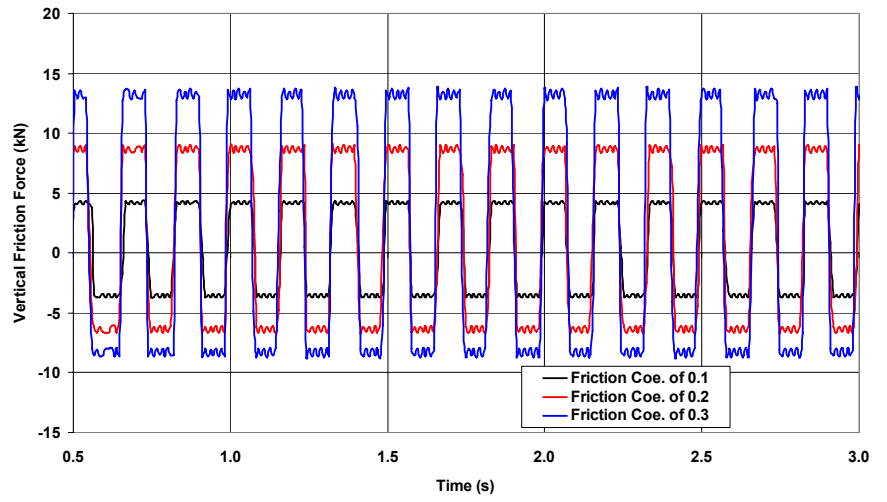

(c) Wedge Friction Force

Fig. 5 Dynamic Responses at $6 \mathrm{~Hz}$
From Fig. 3, it can be seen that when the wagon is given an input profile at a frequency of $2.3 \mathrm{~Hz}$ equal to vertical natural frequency of suspension without damping $\left(\frac{1}{2 \pi} \sqrt{\frac{2 K_{s e}}{0.5 m_{c}+m_{b}}}=2.3 \mathrm{~Hz}\right.$ in which $m_{c}$ - wagon car body mass, $m_{b}$ - bolster mass, and $K_{s e}$ - stiffness coefficient of secondary suspension set) and the friction coefficient on the wedge surfaces is 0.1 , the suspension is in severe resonance so that the suspension force is quickly expanding as shown in Fig. 3 (a), leading to the wheel lifting off the rail as shown in Fig. 3 (b) and the simulation terminated. It means that the friction wedge with friction coefficient of 0.1 does not sufficiently control and limit the resonance of wagon car body. It can be also seen that when the wedge friction coefficients are 0.2 and 0.3 respectively, the friction on wedge surfaces can restrict the wagon car body resonance because it seems large enough to hold the bolster and sideframes together, making very small relative displacement between them so that the suspension force is very small as shown in Fig. 3 (a). Correspondingly, the dynamic wheel load factor is small as shown in Fig. 3 (b).

If the track input frequency is increased slightly from the vertical natural frequency $2.3 \mathrm{~Hz}$ of suspension, for example, to $3 \mathrm{~Hz}$, the dynamic responses are quite different. At first, for all wedge friction conditions, the wagon keeps running without the wheel lifting out of rail at the track input frequency of $3 \mathrm{~Hz}$. Due to $3 \mathrm{~Hz}$ being close to the vertical natural frequency of suspension, the small wedge friction (e.g. 0.1) allows the larger suspension force and dynamic wheel load than those with the high wedge friction (e.g. 0.3) as shown in Fig. 4 (a) and (b). However, if the track input frequency is increased significantly, for example, to $6 \mathrm{~Hz}$, the dynamic responses are just the converse to those at $3 \mathrm{~Hz}$. The high wedge friction (e.g. 0.3) causes the larger suspension force and dynamic wheel load as shown in Fig. 5 (a) and (b) than those by the low wedge friction (e.g. 0.1). From Fig. 5 (b), it can be seen that a higher frequency component superimposed upon the basic frequency component of $6 \mathrm{~Hz}$ for the time history of dynamic wheel load. The wedge friction force also shows this high frequency component as shown in Fig. 5 (c). This frequency at approximately $22 \mathrm{~Hz}$ is very close to the natural frequency of wedge mass-spring system without damping $\left(\frac{1}{2 \pi} \sqrt{\frac{K_{w}}{m_{w}}}=21\right.$ $\mathrm{Hz}$ in which $m_{w}$ - wedge mass and $K_{w}$ - stiffness coefficient of wedge spring). This means that at a high track input frequency, the dynamic characteristic of wedge system has an effect on the dynamic wheel load.

\section{FREQUENCY RESPONSES OF DYNAMIC WHEEL LOAD}

As discussed in above section, the dynamic characteristics of suspension system are quite different at the different track input frequencies. In this section, further simulations have been carried out to illustrate the relationships between the dynamic wheel load and the track input frequency. For better 
presentation of result outputs, a dynamic force factor $\varphi=F_{m x w} / F_{s w}$ is defined where $F_{m x w}$ is the maximum dynamic wheel load and $F_{s w}$ is the static wheel load, and a wheel-unloading factor $\psi=F_{\text {miw }} / F_{s w}$ where $F_{\text {miw }}$ is the minimum dynamic wheel load. The relationships between these two factors and the input frequencies at the wedge friction coefficients of 0.1, 0.2 and 0.3 are shown in Fig. 6 (a) and (b) respectively.

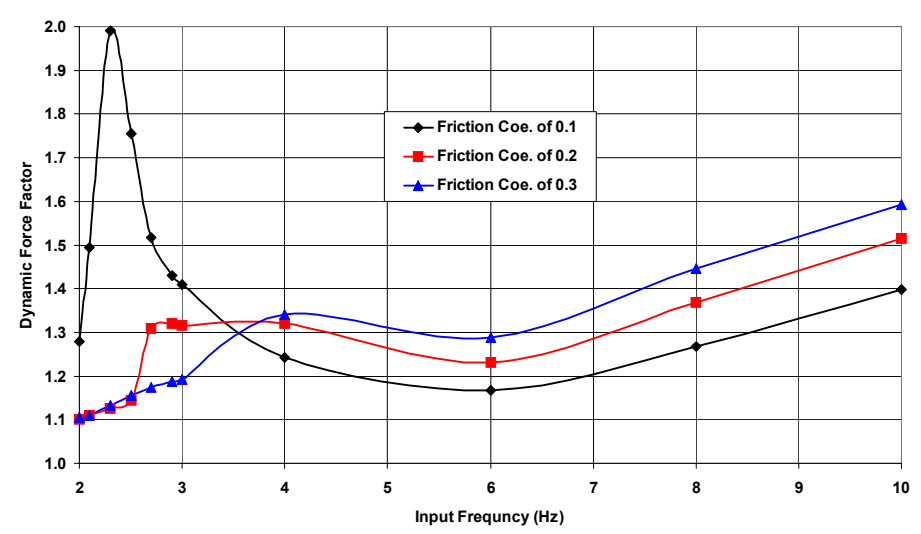

(a) Dynamic Force Factor

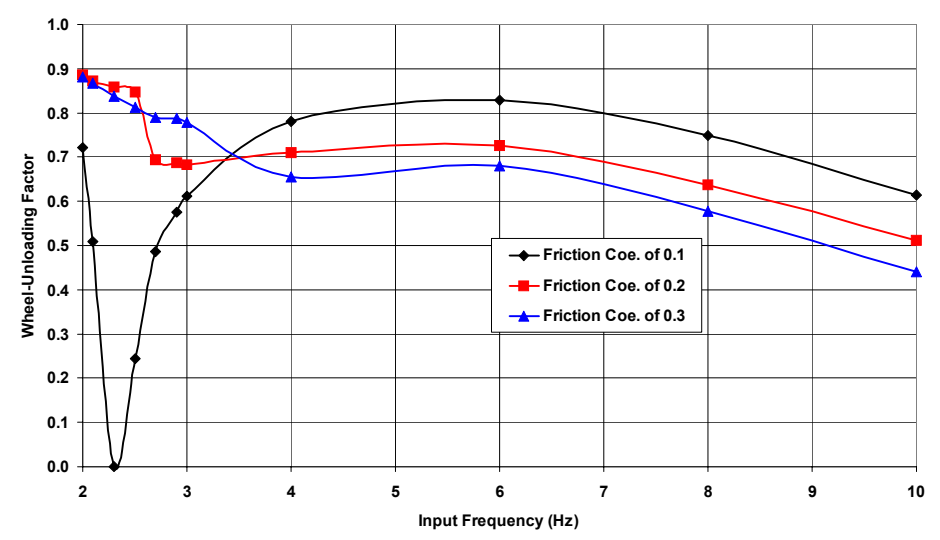

(b) Wheel-Unloading Factor

Fig. 6 Relationships between Dynamic Wheel Load and Track Input Frequency

From Fig. 6 (a) and (b), it can be seen that for the friction coefficient of 0.1 on the wedge surfaces, a maximum value for the dynamic force factor is reached and the minimum value down to the zero (wheel lifting off rail) for the wheel-unloading factor occurs at a frequency of $2.3 \mathrm{~Hz}$. This frequency is equal to the vertical natural frequency of the suspension. For the input frequencies greater than $2.3 \mathrm{~Hz}$, the dynamic force factor reduces, and the wheel-unloading factor increases significantly. However, after $6 \mathrm{~Hz}$, they increase and decrease linearly respectively as the track input frequency increases. The value of 1.16 for the dynamic force factor at $6 \mathrm{~Hz}$, for example, increases to 1.40 at $10 \mathrm{~Hz}$ with an increase of about $20 \%$.

For the wedge friction coefficients of 0.2 and 0.3 , as discussed in above section, the friction on wedge surfaces can restrict the resonance of suspension, making the dynamic force factor and the wheel-unloading factor smaller in the range of input frequency with $2-2.7 \mathrm{~Hz}$ as shown in Fig. 6 (a) and (b). At the input frequency of $2.7 \mathrm{~Hz}$ for the friction coefficient of 0.2 and $4 \mathrm{~Hz}$ for the friction coefficient of 0.3 , the dynamic force factors increase to values of 1.31 and 1.34 from 1.10 and 1.11 at $2 \mathrm{~Hz}$ respectively. Correspondingly, the wheelunloading factors decrease from 0.89 and 0.88 at $2 \mathrm{~Hz}$ to 0.69 and 0.65 at $2.7 \mathrm{~Hz}$ and $4 \mathrm{~Hz}$ respectively. After these two frequencies, the dynamic force factors and the wheel-unloading factors have a small decrease and then increase respectively until $6 \mathrm{~Hz}$. After $6 \mathrm{~Hz}$, they increase and decrease linearly respectively as the track input frequency increases.

It can be also seen that after $4 \mathrm{~Hz}$, the larger friction coefficients on wedge surfaces cause the larger dynamic wheel loads at higher frequency inputs. For example, the dynamic force factors for the wedge friction coefficients of 0.1 and 0.3 are 1.17 and 1.29 at $6 \mathrm{~Hz}$ with the increase of $10.3 \%$, and 1.40 and 1.60 at $10 \mathrm{~Hz}$ with the increase of $14.3 \%$ respectively.

\section{CONCLUSIONS}

Comprehensive wagon-track modelling for simulating the dynamic behaviors of three-piece bogie suspension system with friction wedges has been presented. The effect of wedge friction conditions and wedge mass on the dynamic wheel load has been investigated for a geometry irregularity with short wavelength.

The simulation results show that in the situation of a small friction coefficient (e.g. 0.1) on the wedge contact surfaces and when wagon is running at a speed so that the track irregularity input frequency is close to the vertical natural frequency $(2.3$ $\mathrm{Hz}$ ) of bogie suspension, large dynamic wheel loads are generated, with the dynamic force factor being near 2.0 with wheel lift off. However, with larger friction coefficients (e.g. 0.2 and 0.3 ) on the wedge surface, suspension resonance is restricted, leading to smaller dynamic wheel loads. At track input frequencies higher than resonance, the dynamic wheel load increases proportionally with the track input frequency. Larger friction coefficients on wedge surfaces also result in larger dynamic wheel loads at higher frequency inputs.

\section{ACKNOWLEDGMENTS}

The Centre for Railway Engineering at Central Queensland University, Australia financially supported this research - bogie suspension dynamics.

\section{REFERENCES}

[1] Jenkins, H.H., Stephenson, J.E., Clayton, G.A., Morland, G.W., Lyon, D. The effect of track and vehicle parameters on wheel/rail vertical dynamic forces. Railway Engineering Journal, 1974, 3(1), 2-16.

[2] Newton, S.G., Clark, R.A. An investigation into the dynamic effects on the track of wheelflats on railway wagon. $J$. Mech. Engng. Sci., 1979, 21(4), 287-297.

[3] Clark, R.A., Dean, P.A., Elkins, J.A., Newton S.G. An investigation into the dynamic effects of railway vehicles running on corrugated rails. J. Mech. Engng Sci. 1982, 24(2), $65-76$. 
[4] Cai, A., Raymond, G.P. Modelling the dynamic response of railway track to wheel/rail impact loading. Structural Engineering and Mechanics, 1994, 2(1), 95-112.

[5] Dong, R.G., Sankar, S., Dukkipati, R.V. A finite element model of railway track and its application to the wheel flat problem. Proc Instn Mech Engrs, 1994, 208, 61-72.

[6] Dahlberg, T. Vertical dynamic train/track interaction verifying a theoretical model by full-scale experiments. Vehicle System Dynamics Supplement, 1995, 24, 45-57.

[7] Cai, A., Raymond, G.P. Theoretical model for dynamic wheel/rail and track interaction. Proc. of International Wheelset Congress, Sydney, Australia, 1992, 127-131.

[8] Zhai, W., Sun, X. A detailed model for investigating interaction between railway vehicle and track. Proceeding of $13^{\text {th }}$ IAVSD Symposium, 1993, 603-614.

[9] Ripke, B., Knothe, K. Simulation of high frequency wagon-track interactions. Vehicle System Dynamics Supplement, 1995, 24, 72-85.

[10]Fermer, M., Nielsen, J.C.O. Vertical interaction between train and track with soft and stiff railpads - full-scale experiments and theory. Proc Instn Mech Engrs, 1995, 209, 3947.

[11] Sauvage, G., Pascal, J. P. Solution of multiple wheel and rail contact dynamic problem. Vehicle System Dynamics, 1990, $19,257-272$.

[12] McClanachan, M.J. Investigation of extreme wagon dynamics in Central Queensland coal trains. Master Thesis, 1999, Central Queensland University, Australia.

[13]Frohling, R. D., Howard, M. A. and Kayser, C. R., 1996. Experimental and Theoretical Investigation Load Sensitive Damping in Three-Piece Freight Car Bogies. Proc. of An IHHA Conference on Freight Car Truck/Bogie, Montreal, Canada, pp. 2.3-2.10

[14] Sun, Y.Q., Dhanasekar, M., Roach, D., 2004. Effect of track geometry irregularities on wheel - rail impact forces. Proc. of Conference on Railway Engineering, Darwin, Australia, 03.1-03.7.
[15] Sun, Y.Q., Dhanasekar, M., Roach, D., 2003. Wheel - rail interaction responses due to track geometry irregularities. Proc. of Railway Engineering - 2003, UK.

[16] Sun, Y.Q., Dhanasekar, M., Roach, D., 2002. A 3D model for the lateral and vertical dynamics of wagon - track system. Proc. Instn Mech. Engrs, Vol. 217, Part F, 31-45.

[17] Sun, Y.Q., Dhanasekar, M., 2002. Influence of the railway track parameters to the vertical and lateral impact. Proc. of Conference on Railway Engineering, Wollongong, Australia, 373-382.

[18] Sun, Y.Q., Dhanasekar, M., 2002. A dynamic model for the vertical interaction of the rail track and wagon system. International Journal of Solids and Structures, Vol. 39, 13371359.

[19] Gardner, J. F. and Cusumano, J. P., 1997. Dynamic Models of Friction Wedge Dampers. Proc. of ASME/IEEE Joint Railroad Conference. Boston, MA, pp. 65-69.

[20] Harder, R. F., 2001. Dynamic Modelling and Simulation of Three-Piece Freight Vehicle Suspensions with Non-linear Friction Behaviour Using ADAMS/RAIL. Proc. of ASME/IEEE Joint Railroad Conference, pp. 185-191.

[21]Frohling, R. D., Howard, M. A. and Kayser, C. R., 1996. Experimental and Theoretical Investigation Load Sensitive Damping in Three-Piece Freight Car Bogies. Proc. of An IHHA Conference on Freight Car Truck/Bogie, Montreal, Canada, pp. 2.3-2.10

[22] Berghuvud A. and Stensson A., 2001. Consequence of Nonlinear Characteristics of a Secondary Suspension in a Three-piece Freight Car Bogie. Vehicle System Dynamics, Vol. 36 , No. 1, pp. 37-55

[23] Kaiser, A. B., Cusumano, J. P. and Gardner J. F., 2002. Modelling and Dynamics of Friction Wedge Dampers in Railroad Freight Trucks. Vehicle System Dynamics, Vol. 38, No. 1, pp. 55-82 